\title{
AN ANALYSIS OF THINK GLOBALLY-ACT LOCALLY STRATEGY IMPLEMENTATION IN DEVELOPING RELATIONSHIP OF HEADQUARTERS AND SUBSIDIARIES Case Study of John Clements Consultants Inc., Philippines \& Indonesia
}

\author{
Dilla Noverita
}

\begin{abstract}
John Clements Consultants Inc. (JCCI) is a longestablished and the largest consulting company in Philippines. Its main business focuses on human resource development, especially recruitment and training. Headquarters is in Philippines and its business has grown throughout the world, especially in the Asia-Pacific, Middle-East and United States.

As a multinational company, JCCI has to maintain and develop the relationship with all subsidiaries efficiently. In this case, using qualitative approach and focusing on the relationship with Indonesian subsidiary, this research assesses how headquarters of JCCI formulates and implements company policies governing the relationship between headquarters and subsidiaries. It explores how the headquarters controls, communicates, makes decisions, plans strategy, and gives authority to the subsidiaries.

Moreover, this research analyses how JCCI applies "think globally-actlocally" strategy in its global operations and developing relationship with subsidiaries. It brings the issues of all challenges and obstacles the company has in dealing with subsidiaries. Finally, this research recommends alternative strategies to leverage
\end{abstract}


Gadjah Mada International Journal of Business, January - April 2007, Vol. 9, No. 1

the relationship between headquarters and subsidiaries more efficiently and to minimize the obstacles in cross-cultural management so that the company will be able to strengthen its position in global service market.

Keywords: cross-culture communication; decision making and controlling; international human resource development; international leadership; organizing; strategic planning; think global - act local

\section{Company Background and Profile}

John Clements Consultants Inc. (JCCI) is a consultant company serving its customers with human resource development solutions. It is founded by Mr. Leocadio J. Domniguez in November 1974 together with Mr. John W. Clements from Australia. The company has been serving the world for almost three decades. The business concentrates on a type of service, which is 'The Executive Search'. This service is focused on searching the candidates for top executives for local and multinational corporations. At present time, major clients of this service are Dell Philippines and TVI Pasific (in Manila); Tempo Group and Bakrie Telecom (in Jakarta).

As a pioneer company in Manila that provides services in human resource development and recruitment, the company is strong enough to encounter all obstacles and challenges. Currently, the company is getting more solid and its business develops move progressively. It can be shown that it has been extending its services not only in the area of executive search, but also in providing training, assess- ment programs, recruitment for U.S. companies, etc. As can be seen, not only is the company involved in service industry within local market, but it also operates in international market with various services in human resource development. At the moment, JCCI's divisions have spread mainly in Philippines, Indonesia, and MiddleEast.

The success of John Clements Consultants Group is expressed in its ability to bond with the company's vision, mission, and core values (See Appendix 1).

Since the company's engagement with global operations is getting more complicated, especially due to the prevalence of subsidiaries in different countries, activities of developing relationship between headquarters and subsidiaries must be taken into account. The company as a whole is aimed at achieving the high integration and synergy between headquarters and subsidiaries. The effectiveness of achieving this objective is extremely important for the company's future development.

Based on an interview with Ms. Yardley Young (Senior Executive 
Noverita -An Analysis of Think Globally-Act Locally Strategy Implementation in Developing Relationship...

Vice-President of John Clements Consultants Indonesia), it is known that before Mr. Andi M. Hatta joined the company as the President Director, the level of integrity and synergy was very poor between headquarters and Jakarta subsidiary. It took place as global operational activities were mostly centralized in the headquarters. The subsidiary did not play a significant role in international activities.

As a result, JCCI is suffering from some problems and issues in adjusting itself to the new notion of international management, and struggling to achieve its objectives in international arena. In this point, this research is aimed to cover and analyze problems related to the issue.

The company's subsidiaries or divisions provide different services and serve different types of consumers. These divisions are mainly located in Manila, Philippines whilst other divisions are located in Saudi Arabia and Indonesia. The whole divisions of JCCI are divided based on three broad categories: recruitment, management, and outsourcing (See Appendix 2).

Figure1. Research Process Model

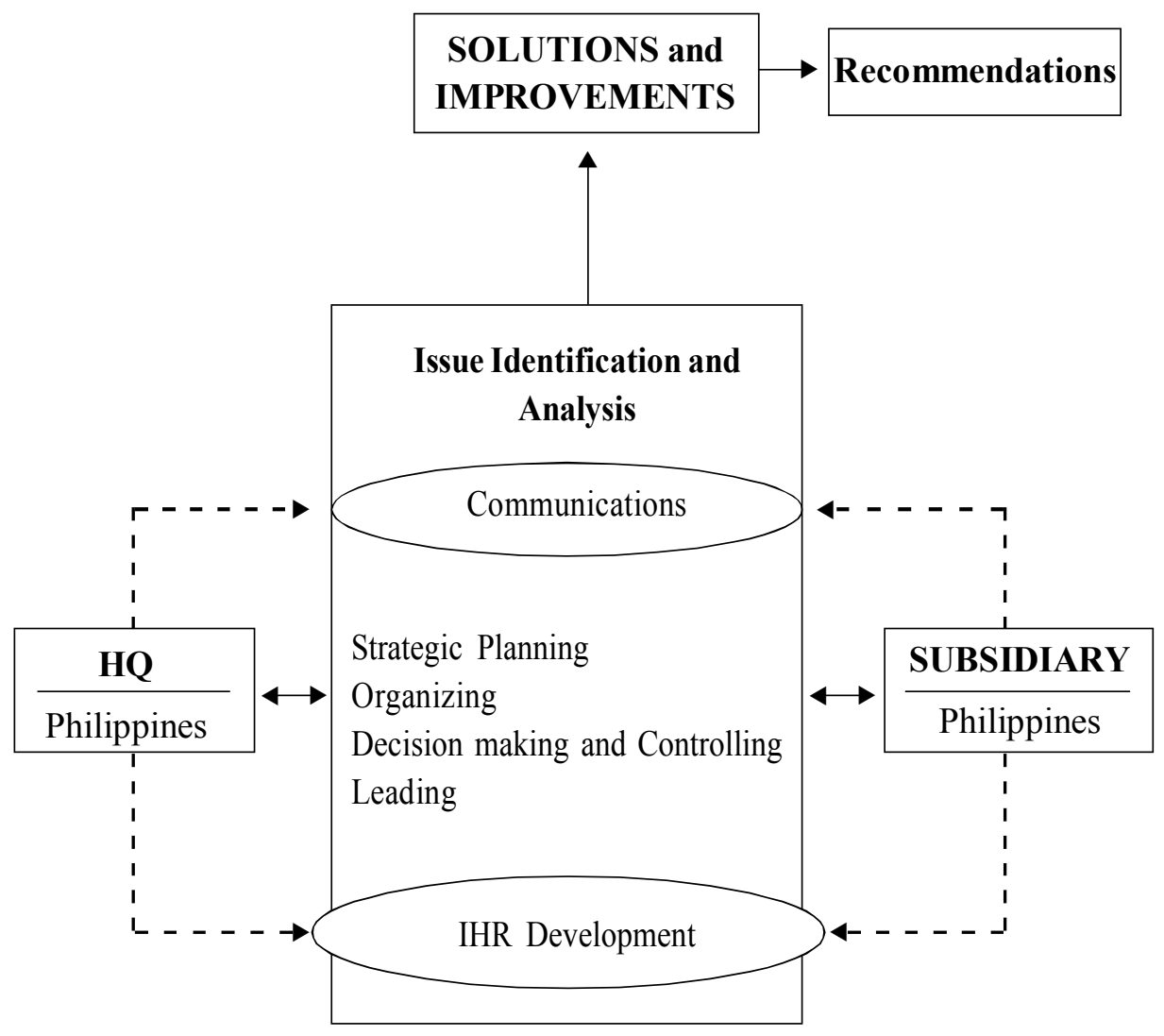




\section{Conceptual Framework}

Using literature in International Management: Culture, Strategy, and Behavior by Hodgetts et al. (2006), all developed theories describe how multinational companies manage their relationships with subsidiaries spreading throughout the world in the content of international strategic management, organizational behavior, and human resource management.

Adapting to the essential concept of the reference above, the mapping of research process is built in order to discover an effective way to establish and extend the relationship between headquarters and subsidiaries (SeeFigure 1).

\section{Research Method}

As the purpose of this study is to examine the best alternatives for a multinational company to adopt the "think globally-act locally" concept with respect to building and developing relationship with its subsidiaries, a qualitative approach is utilized in this research. In order to assess all alternatives provided, this research analyses primary data and information collected from John Clements Consultants in Manila and in Indonesia. The primary data were collected through an in-depth interview with the top management in Indonesian subsidiary and headquarters (See Appendix 4). Meanwhile, the secondary data are taken from the company's profile and reports, sup- ported by some academic and peerreviewed articles.

Based on the theoretical framework, this research utilizes all data required (primary and secondary data) depicted as Figure 1.

\section{The Understanding of Think Globally - Act Locally}

Essentially think globally-act locally is a way for a multinational company to form its strategy to manage the organization globally, and to comply with standard corporate regulations and adapt itself to different cultures, languages, and environment in each subsidiary. In other words, it expresses how the multinational company responds to local demand.

According to Oliver (2000), if a company succeeds in implementing think globally-act locally strategy in its journey to develop businesses in international market, it means that the company is able to adjust itself to local differences and has strong capabilities of survival in the global market.

Therefore, how does the company balance global and local mind-set? Apparently, there are no pure types of coordination. Variables of industry sector, company's strategy, and organizational capability have an influence on the balance between global and local strategies. The global consistency/ local responsiveness grid below will help us understand the extent to which a company balances the glocal mindset in structuring policies to manage all 
Noverita -An Analysis of Think Globally-Act Locally Strategy Implementation in Developing Relationship...

subsidiaries worldwide. Each column in the grid illustrates the degree of global consistency and local responsiveness. Column number three has the highest need for meeting global and local needs (Begley and Boyd 2003)

In choosing a position in the grid, there are some considerations involved. Based on the overall JCCI existence in international market, JCCI lies in grid number two. It is determined by the following factors (Hill 2005):

1. Maximum local responsiveness is compulsory,

2. Requires product customization and market strategy (JCCI keeps changing the market segments referring to the macro-environment intensity),
3. Having low pressure of cost reduction

However, this position can be varied within the company. We will discover the differences in the company's position in the grid according to particular functions in this research.

As a company that struggles in service industry, meeting customer needs is very crucial. It is indeed very pivotal for a human resource consultant to be capable of adapting to the changing macro-environment in local markets. Customer demand in this particular industry is always changing. The variety of demand is formed based on the market intensity.

When certain industry is in the rapid move, it means that the industry

Figure 2. Global Consistency/Local Responsiveness Grids

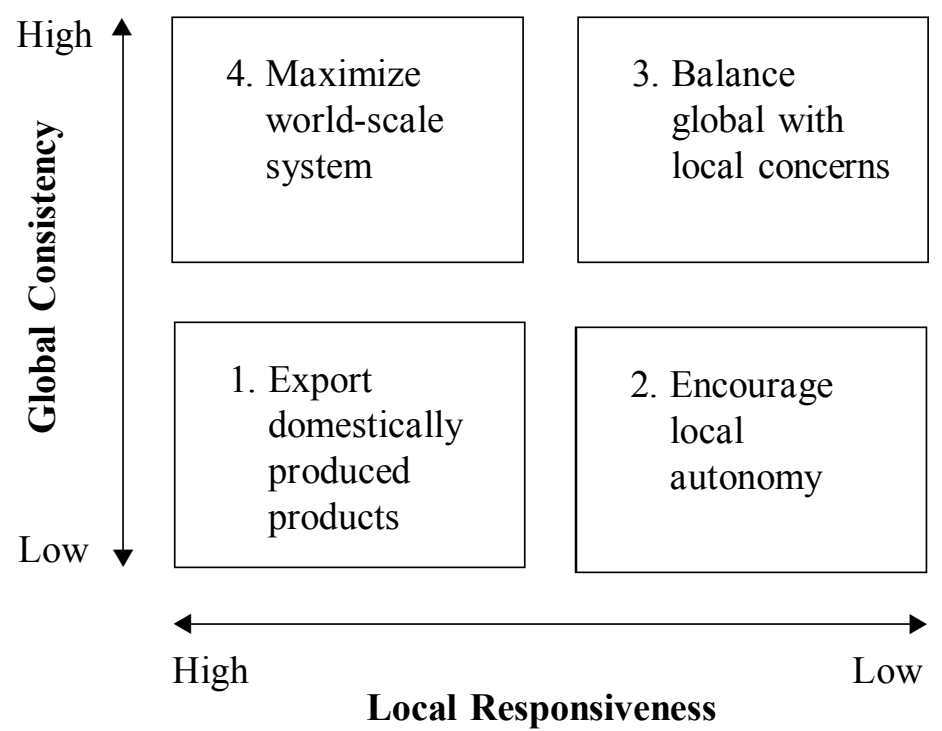

Source: Begley and Boyd (2003) 
requires more employees. Consequently, JCCI is required to have high local responsiveness and also be able to serve the market with its global services.

The building and development of company's policy and strategy with balancing global and local mind-set simultaneously requires individual managers in the company demonstrate glocal mentality. Therefore, the efficiency in managing and developing the relationship between headquarters and subsidiaries would be achieved.

After acknowledging the company's position in the grid, which leads us to recognize the company's international strategy, then we can identify how JCCI implements this strategy in particular functions. It is possible for a company to have different positions in the grid through different activities of each function (Begley and Boyd 2003). Through this point of view, this issue will be discovered.

\section{Problems and Other Issues Identification and Analysis}

The analysis below explores the extent to which JCCI adapts to think globally-act locally mind-set, which is simultaneously exercising a multi-domestic strategy and developing the relationship between headquarters and subsidiaries in order to increase the company's overall performance.

RQ1: As a human resource development consultant company, how does JCCI implement the con- cept of "think globally-act locally" especially in building and developing the relationship with subsidiaries?

\section{Communications}

In terms of communications, Subsidiary Board of Directors mostly communicates with the Board of Commissioners at headquarters (HQ) through e-mail. Nevertheless, telephone, postal mail, and teleconference are also used as media of communications process. The advantage of having various media in communications process helps management control and monitors the Indonesian subsidiary (to be discussed in the next topic).

The use of these media hinges heavily on the level of urgency; teleconference is normally harnessed when something urgent comes up. By using the electronic network through internet, JCCI gets easier to embrace the global mind-set for all employees in all subsidiaries.

Communications between headquarters and Indonesian subsidiary is very much open and transparent in order to achieve integrity. In terms of the necessity for inspiring employees to understand the company's vision, mission, and objectives, the concept of open and transparent communications also prevails between managers and subordinates in Indonesia.

Basically, the Board of Commissioners at HQ and the Subsidiary Board of Directors do not have problems in 
Noverita -An Analysis of Think Globally-Act Locally Strategy Implementation in Developing Relationship...

understanding each other using international languages. In fact, misinterpretation rarely occurs. It means that cultural differences that mostly affect the interpretation and perspectives between two parties do not exert any significant impact on communications process.

Referring to the flow of communications in working environment, HQ and subsidiaries have pursued the upward and downward communications effectively. Subsidiaries feel free to present reports, inputs, and ideas to headquarters, indicating the headquarters' full supports towards the subsidiaries' participation and contributions.

Furthermore, the ease in communications process has made HQ and each subsidiary of JCCI applies crosssale mechanism. Each subsidiary is able to help each other in terms of providing appropriate candidates to fulfil client needs in all host-countries. In other words, each subsidiary has an easy access to resources within JCCI's international market area. It indicates that the company has gained a location advantage in every host-country in which the subsidiary is operating.

\section{International Human Resource Development}

Based on the interview with Charlotte Emilie Q. DeJesus (Executive Search \& Selection Division) during her visit in Jakarta, Indonesia, as an employee being assigned to develop one of the divisions of John Clements Consultants Indonesia, she admitted that she experienced difficulty adjusting herself to the local culture. Basically, her main assignment in Indonesia is to assist and develop the executive search division in Indonesia.

The reason the company sends an expatriate to host-country is to assist the subsidiary to develop the executive search division. What the company has done here can be considered to be maximizing word-scale systems based on the grid (Fig 2). The company exploits location economies by gaining an advantage from transferring the company's core competencies. Unfortunately, due to the hard time of adapting to Indonesian culture, her performance is slightly poorer than hers when she worked in Manila.

According to Ms. Yardley Young, her temporary supervisor in Indonesia, Ms. Charlotte could not participate intensively in developing the executive search division in Jakarta, Indonesia. On account of the shocking period, it was tough for her to produce optimum performance which would bring benefits for Indonesian subsidiary. This condition was also experienced by all expatriates sent to Indonesian subsidiary. As a result, the company's objective of sending employees to Jakarta, Indonesia hardly provides outstanding results.

\section{Strategic Planning}

Based on the interview with Ms. Yardley Young, it is known that after Mr. Andi M. Hatta joined the company, HQ has been giving higher au- 
thority to the subsidiary to make decisions and strategic plans (decentralization).

The concept of decentralization is suitable for multi-domestic strategy, especially for a multinational company like JCCI which operates in service industry and heavily relies on meeting consumer needs.

$H Q$ allows the subsidiary to formulate its own strategic plans whether it is a short-term operational plan (1 year) or a long-term plan (5 years). In general, the Subsidiary Board of Directors uses SWOT analysis as a tool to design the strategic plans (Ruoco and Proctor 1994). This tool, which inquires about the analysis of internal strengths and weaknesses and external opportunities and threat, is very useful since John Clements Consultants operates in service industry which is very sensitive to the macro-environment changes.

The strategic plans proposed by the subsidiary must be presented in Shareholders Annual Meeting. All shareholders together with headquarters and subsidiary representatives will discuss the strategic plans in the forum. In this case, debates, discussion, ideas sharing, and guidance provision normally emerge.

Commonly, the triggers of arguments and debates are derived from the subsidiary's local condition issues. The circumstances here show the company's notion to balance global consistency with local concern (Figure 2). However, because of local information shortage experienced by the $H Q$ as it normally collects information from newspapers, television, and local customers during regular visits to Indonesia, the debates are sometimes quite intense. This happens since the $H Q$ still struggles to create global company plans with high global consistency, but local condition differences could not let this issue resolved.

After agreements are achieved by all members in the Shareholders Annual Meeting, consisting of the Board of Commissioners and the Board of Directors, then the Subsidiary Board of Directors implement all programs proposed.

\section{Organizing}

John Clements Consultants Inc. is divided by its global product divisions. This company's structure is implemented through all subsidiaries. Refer to Appendix 2, some of the divisions in the $H Q$ exist in subsidiaries, but some do not. In subsidiaries, there are six business units comprising four business units and two supporting units (See Appendix 3).

Using an organizational structure based on global product divisions has encouraged local autonomy. Normally, this condition is coherent with a company that exercises a multi-domestic strategy (Hill 2005). This kind of structure has been implemented in subsidiaries as well.

Each division in a subsidiary represents a business unit, and every person in charge as a group head of the business unit has full authority to develop her or his own business (within 
Noverita -An Analysis of Think Globally-Act Locally Strategy Implementation in Developing Relationship...

allocated budget). If only are there unpredictable conditions in the market, they must consult and report directly to the Board of Directors. This concept allows certain business units to become profit centres. For instance, the Executive Search becomes a profit generator in Indonesian subsidiary whilst that of $H Q$ is Staff Builders Asia.

The Subsidiary Board of Directors is responsible and reports to the Board of Commissioners at $H Q$ and all shareholders. The subsidiary's policy is structured by the Subsidiary Board of Directors with $H Q$ approval. Generally, the subsidiary's policies adapt to the $H Q$ 's policies. They are formed with full consideration of company's and employees' interests.

Prior to the transition era, the subsidiary had purely implemented the $H Q$ 's policies with minor adjustments (due to local regulation differences). At the moment, the subsidiary's policies aremoderately different from those of the $H Q$. They are already adjusted to the local culture, characteristics, and government regulations.

Birkinshaw and Hood (1998) discuss that nowadays subsidiaries also have an ability to compete in international market due to distinctive sources that they have. Moreover, it is proven that subsidiaries grow continuously through the development of resources and capabilities. This statement indicates that the organizational changes occurring in JCCI have led to better outputs for the company as a whole.

\section{Leadership}

Before the transition began, leadership style that the Board of Commissioners exercised on their subordinates in Indonesia is closer to an authoritarian style. The flow of information moved one way from top to the bottom. Top management gave clear instructions and made sure that subordinates accomplished their jobs excellently. Because of the significant changes in internal management, the leadership style of the Board of Commissioners has also changed.

At present, the style is inclined to be a participative style. This style is focused on work and accomplishments supported by people orientation. A subsidiary is given full authority to do its jobs with limited involvement of the $H Q$. This situation encourages local autonomy and high local responsiveness (See Figure 2). More interestingly, the drastic changes in the leadership style occurred in a short period of time, right after Mr. Andi M. Hatta joined the company. His existence in the company brings a new paradigm to the company as a whole.

As a multinational company, JCCI surely has a lot of global managers. In this research, Ms. Yardley is used as an example. As one of the leaders managing a subordinate with different national cultures, Ms. Yardley seems not to have the inevitability of different treatments towards different kinds of cultures. Overall, she treats expatriates and local employees equally, although 
she tolerates expatriates more during their adaptation period.

Different leadership styles between the $H Q$ and the subsidiary make the expatriates confused and overwhelmed. Most expatriates experience culture shocks in their first three months. Different leadership styles also make them even more mystified. This is one of the reasons why their performance is lower than their expected performance.

Some leaders at the $H Q$ have the authoritarian style. Intensive internal control would also be extremely needed during working hours. When the expatriates are sent to the subsidiary, they confront with totally different condition in which most leaders at the subsidiary tend to embrace employees empowerment. Consequently, the leadership style of participants does not fit with the expatriates who come from the $H Q$.

However, not all leaders at the $H Q$ adopt the authoritarian style. Based on the interview with Rowena F. Aquino (Professional Staffer Division), her boss in Manila has a democratic style, the same as her leader's style in the subsidiary. This fact reduces the complexity of adaptation working environment adaptation during her stay in Indonesia.

\section{Decision-making and Controlling}

Decision-making and controlling process are intertwined processes. Decision-making is a process through which management chooses actions from several alternatives. Controlling process is a process in which management is assured that the taken actions are related to the objectives.

JCCI uses both decision-making methods: centralization and decentralization (Hodgetts et al. 2006). If it is related to the operational activities, the Subsidiary Board of Directors has full authority in making decisions. There is no approval required from the HQ for the operational activities such as client fees determination, methods of selecting market segments and target markets.

Moreover, in terms of product development, the Subsidiary Board of Directors has authority to diversify the company's products as long as the product variety is still coherent with the company's overall core business. For instance, the type of service such as Training and Consultancy in Indonesia is focused on serving banking and finance industry whilst this condition does not occur in Manila. The HQ only provides general types of training, hence does not specify itself in a particular industry.

The company's policy states that the Subsidiary Board of Directors has authority to decide and execute the strategies as long as they comply with the Article of Association (AoA). Basically, if the Subsidiary Board of Directors formulate and implement strategies that meet the budget standard according to the AoA, then approval from the HQ is not necessarily needed.

If it is related to the investment planning such as the development of 
Noverita -An Analysis of Think Globally-Act Locally Strategy Implementation in Developing Relationship...

Information Technology Unit (this unit has a significant role in being the company's core competence in order to expand businesses), the company's infrastructure, and the selling of company's assets, then the Subsidiary Board of Directors must get approval from the $H Q$.

Both methods that JCCI puts into practice have shown the company's objective to build integrity and synergy between headquarters and subsidiaries, and to respond to local markets at the same time. In other words, both methods of decentralization and centralization are used to support the company's position in balancing global with local concern (Figure 2).

$J C C I$ implements both direct and indirect controlling methods (Hodgetts et al. 2006). Directly, the Board of Commissioners regularly controls the Indonesian subsidiary by visiting Jakarta three to four times annually. Each visit normally takes a week long period. In conducting indirect control, the Subsidiary Board of Directors sends reports through e-mail or making a call if it is considered an urgent situation.

The $H Q$ deeply focuses on financial performance and technology protection in possessing controlling activities. The reason the company obligates technology protection as one of the tools extremely needed to be controlled is that the success in recruitment business depends heavily on the technology and human resource systems (although human resources can still develop along with their experi- ences). The company needs to have strong database systems to save, gather, and update a candidate's historical data be needed for satisfying client needs. For instance, John Clements Consultants Indonesia is currently developing its IT systems in order to be connected to each candidate through internet.

The $H Q$ is also concerned about controlling quality performance. It indicates that JCCI concentrates on the importance of excellent service quality. Basically, the specific areas that need to be controlled are:

1. Ability to meet the length of service delivery process standard

2. Ability to satisfy the quality standard of human resources

With respect to setting the standards above, the HQ gives authority to the Subsidiary Board of Directors due to the necessity to adapt to local culture and condition whilst gaining efficiency at the same time. For instance, before the transition era, service delivery process sometimes took a long period of time owing to waiting for interviewers from the HQ to come to Indonesia. Currently, this condition does not exist since the subsidiary has authority to conduct interviews itself without the HQ interference. Furthermore, the Subsidiary Board of Directors is setting a standard of quality manual for the company's interest. However, this is still in process and takes some time as it waits for headquarters approval and recognition.

RQ2: Are the implemented concepts already coherent with all the 
needs in the global service market? What are the other best alternatives?

Based on the findings, problems related to the cross-cultural human resource management and communications, and important aspects related to the strategic planning need to be solved.

\section{Solutions}

\section{Building Local Culture Awareness for Expatriates}

As a multinational company that attempts to gain efficiency through location economies, JCCI sends expatriates who have high expertise and competences from the HQ to subsidiaries requiring assistance. Basically, this is one of the company's objectives, which is to achieve cost efficiency and continuous improvement. Furthermore, it reflects the fact that being a consultant company in service industry requires that JCCI separate service process from service provider.

There are several criteria that must be satisfied by expatriates in international assignments (Hodgetts et al. 2006):

1. Have adaptability to cultural change,

2. Have good physical and emotional health,

3. Have good education and experiences,

4. Obtain language training,

5. Have high motivation for international assignments (normally jun- ior managers are more eager to accept international assignments and willing to learn other cultures), and

6. Have leadership ability.

Before the HQ decides to send expatriates to a subsidiary, the HQ must consider the above important criteria so as to avoid cost and time inefficiency. According to Neupert et al. (2005), companies can develop international managers in two ways. The first is trial-and-error method, which is costly and takes longer time. The second is through providing training and education programs that may develop necessary skills. JCCI still implements the first method, leading to higher costs and losses. It is proven that international managers are mostly sent back to their home country because of poor performance.

Different cultures, manners, and perspectives can exert significant effect on management effectiveness. It is very crucial for international managers to have a common set of skills: cultural understanding and awareness, professional skills including leadership and management skills (Neupert et al. 2005).

More interestingly, local managers and employees must also have the common skills in working together with expatriates. It is suggested that local employees also obtain special training to develop their interpersonal skills, including a review of business basics, communications and cultures (Neupert et al. 2005). 
Noverita-An Analysis of Think Globally-Act Locally Strategy Implementation in Developing Relationship...

\section{Conducting Special Trainings for International Managers and Expatriates}

Training is a very important system, not only for developing individual effectiveness but also for enhancing the ability of organization to achieve effectiveness and adaptability to a holistic approach. Many companies see training as a strategic priority rather than as a tactical response since they see training as a medium to encourage learning environment (Jain and Agrawal 2005). As a multinational company, JCCI needs to develop its training program in order to get higher ability to be more effective and competitive in international market.

Based on the research of Deshpande and Visweswaran (1992), there is a positive relationship between cross-cultural training for expatriates and psychological wellbeing, social skills with host country, an ability to adjust, and the development of correct perception of host culture and the people. Cross-cultural training can bring success to expatriates in terms of job ability, relationship ability, language ability, and family adaptability (Jain and Agrawal 2005).

This training will increase individual ability to understand and adjust to unique local cultures and conditions. Most importantly, this training will be a requisite to be delivered before their posting in host country/subsidiary (Neupert et al. 2005). It is strongly suggested that JCCI conduct cross-cultural trainings for expatriates and senior managers in order to avoid work inefficiency.

\section{Deeper External Local Environment Analysis}

What the $H Q$ has currently implemented is already appropriate towards the company's organizational structure and strategy. However, centralization and decentralization authority arouses the complexity of coordination. The Subsidiary Board of Directors is allowed to originate strategic plans, and the Board of Commissioners has authority to approve them. Therefore, debates and arguments often emerge during Shareholders Annual Meeting. Nonetheless, due to the company's position in Column 3 (Figure 2) and the importance of local responsiveness, it is accurate that the company should hold onto the decentralization concept (Hill 2005).

Nevertheless, it is important for the $H Q$ to expand its knowledge by acquiring information on local condition in the host country. David (2005) finds that in the stage of strategy formulation, executives and managers need to do external assessments by analyzing economic, social, cultural, demographic, environmental, political, governmental, legal, technological, and competitive forces. Hence, through this deep analysis, they will be able to make a list of opportunities and threats of external factors. 
Gadjah Mada International Journal of Business, January - April 2007, Vol. 9, No. 1

This activity will influence the company's strategy generation process. Although these assessments are mainly conducted by the Subsidiary Board of Directors, but it is crucial for the HQ to take deep acknowledgment of local macro-environment in terms of flexibility in reaching agreements.

\section{Global Leader Roles}

The most important point for a leader in a multinational company is how the management is able to harmonize between individualism and collectivism points of view in order to achieve high productivity (Alkhafaji 1995).

According to Muna (2006), there are seven roles that global leaders must play:

1. Leaders have a responsibility for preparing and selecting human resources, taking care of them, and developing them.

2. Leaders must be able to work in a team, wise in delegating and empowering, and helping each other when their subordinates and colleagues are in trouble.

3. Leaders have excellent versatility as they may create the company's long-term value.

4. Leaders must know how to give direction towards goals that must be achieved.

5. Leaders must possess global mindset, have a broad point of view, be aware of cultural differences, and be able to handle different consumer preferences.
6. Leaders must have an ability to negotiate with different customers, clients, suppliers, government officials, etc.

7. Leaders must be able to handle multiple tasks and to balance work, family, and personal life.

Besides, there are alternative improvements that could develop the relationship between headquarters and subsidiaries.

\section{Improvements}

\section{Awareness of Cross-cultural Communication Barriers and Channel Capacity}

More importantly, management has to maintain the cross-cultural communications between headquarters and subsidiaries. It means that the company has to consider local culture in communications process. The finding shows that JCCI gains high effectiveness through high values of communications systems and location economies. However, there is a lack of cultural-difference awareness during the communications process due to historical success.

Heretofore, JCCI already has electronic network systems, which link subsidiaries and headquarters through internet. There are several advantages for companies when they use network communication systems:

1. It can improve the communications ability to determine information coming from more than one source. 
Noverita-An Analysis of Think Globally-Act Locally Strategy Implementation in Developing Relationship...

2. The company can obtain useful information from governmental sources.

3. The managers could reduce the number of paperwork involved due to manual communications, and could escalate the speed of decision-making between headquarters and subsidiaries.

Nevertheless, some problems also appear. For instance, the company has to be concerned about the way through which it exercises the networking strategy, such as channel complexity, languages, and cultures. These problems affect the ongoing communications between headquarters and subsidiaries since different countries and cultures bring different languages and interpretation. This may influence the direction, amount, and types of communications. Therefore, some companies provide special personnel international trainings for employees to overcome the problems (Ronen 1986).

Additionally, the most significant factor in maintaining the communications network is the appointment of skilled people who can communicate in both host and home countries (Ronen 1986). Top managers of JCCI are able to speak in international languages, both oral and written languages. Moreover, with their gradual visits to Indonesia and Manila, they have learned about explicit artefacts of local culture and about product differences in each culture.

\section{Awareness of Decision Roles}

Bartlett and Ghoshal (1997) provide a post-transformational theory as a result of expansion in hierarchy model of organizations in creating an organizational framework of multinational company. This theory is useful for JCCI for achieving high integrity of coordination.

The hierarchy model discusses the vertical model of managers, starting from top managers who are responsible for designing strategies and controlling resources to middle managers who analyze all input information and distribute resources properly under the auspices of the top managers. Hence, frontline managers implement the decisions made by the top managers.

Post-transformational theory is an improvement to the hierarchy model. According to this theory, the top managers become institutional leaders, the middle managers have higher contributions to increasing the company's benefits, and the frontline managers concentrate more on productivity, innovation, and the company's growth (Bartlett and Ghoshal 1997).

This organizational framework explains three perspectives of decision roles that multinational companies have to consider:

- Headquarters' role determines decision-making within product life cycle model and internationalization process. Subsequently, the de- 
cisions will be passed to subsidiaries.

- Subsidiaries' choice determines subsidiaries' authority to make decisions by utilizing the network model of multinational company to deliver any final decisions to headquarters.

- Local environment determinism determines the effect of different local environment, such as customers, competitors, suppliers, and government rules, on subsidiaries' decisions.

In order to achieve high integrity in generating an ideal organizational framework and subsidiaries development, three perspectives above should be taken into account for achieving the balance between headquarters' and subsidiaries' authority. This is very pivotal especially because of the physical separation of one member of the Subsidiary Board of Directors from the others.

In other words, subsidiaries make decisions by considering the changes in local environment, referring to the headquarters' requirements and opportunities in local environment (Birkinshaw and Hood 1998).

\section{Aware of Organizational Inertia}

Hypothetically, the changes in organization are very difficult to be accomplished. However, JCCI could manage all the changes very well so far; for example, the practices of decision-making, controlling, planning strategy, leadership style, and company's policy have experienced dramatic changes. All parties involved both at headquarters and at subsidiaries respond positively to the changes. Nonetheless, JCCI still encounters difficulty reaching integrity where headquarters and subsidiaries still strive for reaching the same perspective in the Shareholders Annual Meeting. The company must be aware of organizational inertia so as to be able to better organize its management and does not meet obscurity in integrating mechanism.

These are the sources of inertia that might slow the pace of organizational changes (Hill 2005):

1. The reallocation of existing distribution of power and influence within organization which will result in employee's resistance to changes.

2. The alteration of organizational culture expressed in norms and value systems.

3. The difficulties of accepting a new business paradigm due to managers' preconception about the appropriate one.

\section{Appropriate Decision-Making Method}

Decision-making method can be divided into two methods: centralization and decentralization. Referring to the concept of think globally-act locally, many factors need to be considered regarding the decision-making method. 
Noverita -An Analysis of Think Globally-Act Locally Strategy Implementation in Developing Relationship...

According to Kono (1999), if a multinational company provides related diversification products, it tends to have a centralized decision-making method for research and development in international market. In this case, there are some principles of decisionmaking that JCCI should follow:

- The upper level management has to make decisions based on information on long-term external environment. On the other hand, the lower level management is given full authority to make decisions within the operational area.

- The integration of activities is not within rules and policies only, but it is a total integration of activities between top management with lower level management.

- However, there is a limitation of information access. Therefore, the HQ must delegate authority to subsidiaries very well. This condition can motivate lower level employees to achieve higher performance.

On the other hand, if a multinational company produces unrelated diversification products, it is probably better off with the decentralization concept of decision-making, especially if the diversification does not come from internal development.

\section{Creating Procedural Justice}

Based on Ellis (2000), there are five characteristics of decision-making in order to generate the procedural justice amongst decision makers in headquarters and subsidiaries. The pro- cedural justice is important to achieve since it can lead to the company's ability to analyze the effectiveness of subsidiaries within a global network.

The major five characteristics of strategic decision-making process are:

- There is a bilateral communication between individuals in headquarters and subsidiaries, leading to knowledge, perceptions, expertise, and ideas transfer.

- The emergence of fruitful discussion between the managers of headquarters and those of subsidiaries in order to create challenges to headquarters in analyzing strategies.

- The acknowledgment of subsidiaries environment by HQ means that the HQ takes the environmental changes into account in creating strategic decision-making.

- Decision-making process consistency will enhance the HQ's and subsidiaries' motivation to achieve global strategic objectives.

\section{Applying Agency Theory}

Based on O'Donnel (2000), there are two theories supporting the concept of controlling headquarters and subsidiaries, which are agency theory and interdependence theory. However, if we refer to the company's condition, agency theory could be beneficial for improving controlling method.

The main objective of these theories is to analyze problems emerging in foreign subsidiaries with various external environment, internal skills, and competencies. Agency theory dis- 
cusses the role of agency in controlling subsidiaries when they make decisions. According to this theory, the HQ should provide an expatriate (senior manager) to be the agent for assessing the subsidiaries' operations. The purpose of the agency is to reduce risk caused by subsidiaries formulating the company's rules and autonomy.

This theory suggests that subsidiaries be given autonomy to make decisions and analyze all information needed for their own matters. Meanwhile, strategies and operational activities are controlled by the HQ. There are some problems that will probably arise. The implementation of this theory involves high cost and difficulty in appraising the agent's performance (O’Donnel 2000).

The agency theory supports the concept of think globally-act locally strategy in controlling the HQ and subsidiaries relationship. This concept is very effective to implement since JCCI relies on the Subsidiary Board of Directors to control regular operations.

\section{Knowledge Flow Control}

Apparently, JCCI concentrates more on financial, technology, and quality performance in controlling systems. According to Chung et al. (2000), there are three main areas that the HQ must consider in controlling subsidiaries and simultaneously applying appropriate leadership notion. One of the areas is not the one that company is focusing on.
The area is knowledge flow control; either it is an output flow (in which subsidiaries transfer the knowledge to other corporations) or an input flow (in which subsidiaries import knowledge from other parts). Both flows influence the control volume of the HQ. For instance, when knowledge inflow increases in subsidiaries, it will affect the subsidiaries' actions. On the other hand, when knowledge outcome escalates, the HQ will have difficulty determining and controlling various outputs.

\section{Recommendations}

1. JCCI needs to develop the awareness of cross-cultural communications barriers. This is very crucial since using internet as a medium of communications does not eliminate the barriers of communications.

2. In order to develop the competency of human resources, JCCI needs to build cross-cultural training programs for international managers and expatriates.

3. The HQ should take a deeper external analysis of local environment and expand the sources of information in order to achieve synergy in strategy formulation.

4. It is essential for the company to be aware of organizational inertia which mostly occurs when organizational changes take place. The awareness must be built in order to avoid inefficiency in responding to the changes. 
Noverita -An Analysis of Think Globally-Act Locally Strategy Implementation in Developing Relationship...

5. All leaders of JCCI must pay attention to their specific roles in leading and managing subordinates from different cultures. As global leaders, they must have a broad point of view and be responsive to different customer preferences and local conditions.

6. It is recommended that JCCI creates procedural justice in decisionmaking process so that the balanced authority of headquarters and subsidiaries will be effective in realization stage. Moreover, to improve controlling method, JCCI should apply the agency theory which would provide a concrete evaluation on subsidiary performance.

\section{Limitation}

Because of data limitation caused by difficulties in conducting interviews with some employees involved in the company's headquarters, there might be some missing information needed for this research. Customers list for each company's products is also could not be fully provided due to limited capacity. However, somehow this concern does not bring significant effect towards the whole research, analysis, and strategically thinking. The exploratory nature of this research provides results that can be used by academics and practitioners as a basis upon which to build on our knowledge of think global - act local concept towards strategic implementation.

\section{References}

Alkhafaji, F. A. 1995. Competitive Global Management, Principles and Strategies. USA

Bartlett, C., and S. Ghoshal. 1997. The myth of the generic manager. California Management Review 40 (1): 92-116

Begley, M. T., and P. D. Boyd. 2003. The need for a corporate global mind-set. MIT Sloan Management Review_44 (2): 25-32

Birkinshaw, J., and N. Hood. 1998. Multinational subsidiary evolution: Capability and charter change in foreign-owned subsidiary companies. Academy of Management Reivew 23 (4): 773-795

Chung, L., P. Gibbons, and H. Schoch. 2000. The influence of subsidiary context and head office strategic management style on control of MNCs: The experience in Australia. Accounting, Auditing and Accountability Journal 13 (5): 647-666

David, F. 2005. Strategic Management. Prentice Hall.

Deshpande, S. P., and C. Vishweswaran. 1992. Is cross-cultural training expatriate managers effective: A meta analysis. International Journal of Intercultural Relations 16: 295-310.

Ellis, K. 2000. Strategic contexts, knowledge flows, and the competitiveness of MNCs: A procedural justice approach. Competitiveness Review 10 (1): 9-24 
Gadjah Mada International Journal of Business, January - April 2007, Vol. 9, No. 1

Hill, W. C. 2005. International Business: Competing in the Global Marketplace. New York: McGraw-Hill.

Hodgetts, M. R., F. Luthans, and P. J. Doh. 2006. International Management: Culture, Strategy and Behavior. New York: McGraw-Hill.

Jain, K. R., and R. Agrawal. 2005. Indian and international perspectives on employee training practices: A trend report. South Asian Journal of Management 12 (1): 7991.

Kono, T. 1999. A strong head office makes a strong company. Long Range Planning 32 (2): $225-236$.

Muna, A. F. 2006. Seven leadership roles. International Journal of Commerce and Management 16 (1): 51-57.

Neupert, E. K., C. Baughn, and T. T. Lam Dao. 2005. International management skills for success in Asia: A needs-based determination of skills for foreign managers and local managers. Journal of European Industrial Training, 29 (2/3): 165-180.

O’Donnel, W. S. 2000. Managing foreign subsidiaries: Agents of headquarters or an interdependent network. Strategic Management Journal 21: 525-548.

Oliver, R. 2000. New rules for global market. The Journal of Business Strategy 21 (3): 79.

Ronen, S. 1986. Comparative and Multinational Management. Canada

Ruoco, P., and T. Proctor. 1994. Strategic planning in practice. Marketing Intelligence and Planning 12 (9): 24-30 
Noverita -An Analysis of Think Globally-Act Locally Strategy Implementation in Developing Relationship...

\section{Appendix. 1}

\section{JCCI Vision \& Mission}

Vision : Pan Asia's Blue Chip Human Resource Solutions Leader with Minimum \$3M EBIT

Mission : We are the number one Human Resource Solutions Company aspiring to be Pan Asia's Blue Chip Human Resource Solutions Leader

Core Values:

- Integrity and Professionalism

- Energy

- Target and Action-Oriented

- Service Quality and Customer-Oriented

- Proactive to Change

- Passion for Excellence

\section{Appendix.2.}

\section{Divisions/ Subsidiaries of John Clements Consultants Group}

\section{RECRUITMENT}

1. John Clements' Executive Search \& Division (ESSD), located in Manila. Its service concentrates on finding executive talents that fit the client's requirements and also playing a significant role in the careers of senior executives currently steering local and multinational companies in Philippines. JCCI began its business in this particular service.

2. Professional Staffers, located in Manila. Its service focuses on personnel recruitment from Junior Management Rank and File. It becomes a strong provider of permanent professional staff and junior executives. The services are: full cycle recruitment service, unbundled recruitment service (sourcing, paper screening, interviewing, testing and reference checking).

3. EDI-Staffbuilders International Inc. (EDI-SBII), located in Manila and Saudi Arabia. Its function focuses on overseas recruitment firm major in Middle East and Pacific Rim. EDI-SBII provides search in all level of Filipino personnel such as executive, professional highly technical, skilled and operative.

4. PT John Clements Consultants Indonesia (JCCI), located in Jakarta, Indonesia. Its service creates so many opportunities in Indonesians leading global, national conglomerates and local companies. The services are: professional staffing services, payrolling services, business process outsourcing, and testing services. 
Gadjah Mada International Journal of Business, January - April 2007, Vol. 9, No. 1

5. International Healthcare Consulting, located in Manila. Its service specializes in the recruitment of top-tier Filipino healthcare professional providing long term career opportunities in the U.S

\section{MANAGEMENT}

1. Shop'nCheck Philippines, located in Manila. This division is a licensee of Shop'n Check Worldwide (www.shopncheck.com) which leader in mystery shopping. This division supported the company in order to conduct effective and objective programs which deliver measurement of customer satisfaction and constructive feedback to the clients.

2. John Clements Consultants Inc, Assessment \& Development Center, located in Manila. This division is designed to give customers make the best decisions when recruiting and promoting employees and also identifies their strength and weaknesses so that they can achieve excellent performance in their career-path.

3. Human Resource Development Consulting, located in Manila. Its service concentrates on corporate training programs for maximum profitability such as six sigma, sales and marketing training program and so on.

\section{OUTSOURCING}

1. Staffbuilders Asia, located in Manila. Its service focuses on staff augmentation, project management and service contracting. This division shows that the company has capability in subcontracting a whole functional activity.

2. Speednet, Inc., located in Manila.

\section{Appendix.3}

\section{Four Main Divisions of Subsidiary:}

Executive Search, Professional Staffers, StaffBuilders, Training and Consultancy. Two supporting units: Human Resource Development and Finance \& Accounting One upcoming unit: Operational.

\section{Subsidiary Board of Directors:}

1. President Director : Andi Moh.Hatta

2. Deputy of President Director : Grace Sorongon (whose base is in Manila, Philippines)

3. Former Senior Executive Vice President : Yardley Young (who just resigned not along ago after 11 years of dedication) 
Noverita-An Analysis of Think Globally-Act Locally Strategy Implementation in Developing Relationship...

\section{Appendix. 4}

\section{INTERVIEW LIST:}

1. Yardley Young :

Former Senior Vice President of John Clements Consultants Indonesia

2. Charlotte Emilie Q. DeJesus : Executive Search \& Selection Division, Manila

3. Rowena F. Aquino:

Professional Staffers Division, Manila. 